\title{
RETURN AND TOTAL FACTOR PRODUCTIVITY OF PUBLIC INDUSTRIAL COMPANIES
}

\author{
Sn. Konstantinova ${ }^{1 *}$, A. Konarev ${ }^{2}$, G. V. - Georgieva ${ }^{1}$ \\ ${ }^{1}$ Faculty of Economics, University of Food Technologies - Plovdiv, Bulgaria \\ ${ }^{2}$ Technologies and Innovations Corporation PLC - Plovdiv, Bulgaria
}

\begin{abstract}
Total factor productivity is a complex factor that affects not only corporate growth but also other key parameters of industrial companies. This paper explores the impact of this factor on the return on capital invested in these companies. Based on the example of a group of public companies whose shares are traded on the main and alternative markets of the Bulgarian Stock Exchange - Sofia, the level and the dynamics of the return and the total factor productivity is analysed. Dependencies are identified and opportunities for intensifying corporate growth are revealed.
\end{abstract}

Key words: return, total factor productivity, corporate growth, industrial companies, capital

\section{INTRODUCTION}

Over the last decade productivity worldwide (whether measured as labour productivity or total factor productivity) remains stagnant despite the exponential growth in technological progress and investment in innovation [1]. According to Haskel \& Westlain "financial crisis, reduced investment, but not enough to explain the entire decline in labour productivity. In fact, the main part of the productivity slowdown is due to a reduction in total factor productivity." In the present work, the authors aim to explore how total factor productivity has affected returns, measured in two versions:

(a) as a return on total assets (operational efficiency of business);

(b) as return on equity (financial performance).

\section{MODELS, RESULTS AND DISCUSSION}

As an object is used public companies whose results can hardly be manipulated by managers because of their open nature. The analytical period is relatively long (2007-2017), with data from pre-crisis 2007 being deliberately used to start the survey period.

Correspondence to: Assoc. Prof. Snezhinka Konstantinova Stoyanova, PhD, Faculty of Economics, University of Food Technologies Plovdiv, Bulgaria, 4002 Plovdiv, 26 Maritsa Blvd., Cell Phone: +359878 384372, E-mail: sks_ko@abv.bg
The selection of the companies is targeted and the authors' opinion is to study the best performing industrial companies on the Bulgarian Stock Exchange - Sofia in the following way of grading:

First level: includes all industrial companies, engaged in the calculation of the main stock index - SOFIX:

- Sofharma AD;

- M+C Hydraulic AD;

- Sirma group AD.

Second level: Includes the Premium Market segment in the primary market:

- Monbat AD;

- Korado Bulgaria, AD.

Third level: includes a Stock Segment Standard in the main market: everyone else.

The sample did not include companies from Alternative Market (Base), due to their weak trading and low capitalization reflection of their unsatisfactory results.

From the original list were dropped, those who did not achieve corporate growth for the period under review. This formed a group of 14 companies whose results were examined.

To determine the total factor productivity TFP used model designed and presented in our other research. [3]. The model is as follows: 
$\frac{A_{t}^{i}-A_{t-n}^{i}}{A_{t-n}^{i}}=\frac{Y_{t}^{i}-Y_{t-n}^{i}}{Y_{t-n}^{i}}-C d_{i} \frac{K_{t}^{i}-K_{t-n}^{i}}{K_{t-n}^{i}}-L a_{i} \frac{L_{t}^{i}-L_{t-n}^{i}}{L_{t-n}^{i}}$

where

$A_{t}^{i}$ - total factor productivity of the i-th dairy company in year $t$ (year 2016);

$Y_{t}^{i}$ - net sales of $\mathrm{i}$-th company in $\mathrm{t}$-th year;

$C d_{i}$ - capital intensity of i-th company's production for the relevant period (20072016);
$L_{t}^{i}$ - total amount of labor costs of i-th company for the year $t$;

$L a_{i}$ - labour intensity of i-th company's production for the same period;

$N$ - number of years of the analysed period.

After processing the primary data of industrial companies and their inclusion in model structure following results were obtained about the impact of major factors on corporate growth, measured in this study by the increase in net sales revenue - Table 1:

Table 1. Factor impact on corporate growth (2007-2017)

\begin{tabular}{|l|c|c|c|c|}
\hline \multirow{2}{*}{ Industrial companies } & \multicolumn{4}{c|}{ Corporate growth $(\%)$} \\
\cline { 2 - 5 } & Total & Capital & Labour & TFP \\
\hline 1. Sopharma AD & 24,50 & 365,00 & 80,40 & $-420,90$ \\
\hline 2. Sirma group AD & 534,38 & 324,01 & 4,01 & 206,36 \\
\hline 3. Korado Bulgaria AD & 73,95 & 167,82 & 20,88 & $-114,75$ \\
\hline 4. Hydraulic Elements and Systems AD & 26,91 & 82,55 & 25,21 & $-80,85$ \\
\hline 5. Alkomet AD & 45,59 & 215,11 & 25,63 & $-195,15$ \\
\hline 6. Neochim AD & 21,75 & 2,36 & 5,56 & 13,83 \\
\hline 7. Elhim Iskra AD & 67,42 & 30,93 & 4,08 & 32,41 \\
\hline 8. M+C Hydraulic AD & 13,40 & 95,66 & 19,34 & $-101,60$ \\
\hline 9. Yuri Gagarin AD & 160,01 & 55,69 & 2,81 & 101,51 \\
\hline 10. Monbat AD & 159,69 & 84,49 & 0,72 & 74,48 \\
\hline 11. Lavena AD & 805,08 & 625,46 & 15,25 & 164,37 \\
\hline 12. EMKA AD & 50,72 & 17,92 & 6,03 & 26,77 \\
\hline 13. Formoplast AD & 475,62 & 13,57 & 0,04 & 462,01 \\
\hline 14. Asenova Krepost AD & 59,19 & 18,75 & 9,24 & 31,20 \\
\hline
\end{tabular}

Analysis of data from Table 1 allows distinguishing four groups of companies depending on the relation "growthproductivity".

The first group concern three companies from three different sectors of the industries that have generated very high corporate growth:

- Sirma group AD - information technology;

- Lavena AD - perfumery, cosmetics, biotechnology;

- Formaplast AD - engineering company.

It's interesting, that for all three companies their total factor productivity is a significant contribution to corporate growth.

The second group of companies has achieved high growth:

- Yuri Gagarin AD - 160.00\%;

- Monbat AD - 159.59\%.

The impact of total factor productivity on the corporate growth of these two companies is also significant - around $50 \%$.
The third group refers to companies, which achieve moderate or low corporate growth, as TFP contributed to this growth: Neochim AD 21.75\%; Elhim Iskra AD - 67.42\%; EMKA AD - 50.72\%; Asen's Kreopost - 59.19\%. Though not so pronounced, the impact of TFP on growth is positive.

A fourth group was formed, including five industrial companies with moderate or rather low growth, where TFP had a negative impact on corporate growth. Generally a question occurs "Can TFP have a negative value?". Our answer is categorical: "Yes!". The arguments in this respect are as follows: TFP is a complex factor that includes two sets of factors [3]:

Group I - stimulating corporate growth by implementing new technologies, new machinery, new combination of resources, new forms of organization, new methods of marketing, etc.

Group II - retaining corporate growth by reducing the amount of raw materials, the decrease in market prices, loss of markets, increased competitive pressures, increasing environmental constraints oversupply in the 
domestic and global market, embargoes and international sanctions to import or export and others.

Solow's [4] model of economic growth three factors is included at national level: the amount of physical capital input of labour resources and the TFP, which includes all other factors outside labour and capital. Therefore, some authors point out [2] that all of these factors should be called "multifactor performance", in their view, the name "TFP" is confusing.

The arguments presented give reason to assume, that is acceptable at certain times listed companies to realize negative TFP values dominated by the set of retention factors. In the survey presented, the number of these companies is relatively small, with their corporate growth being stimulated mainly by additional labour costs. The research convincingly shows that TFP has had a positive impact on the corporate growth of the whole set of analysed companies, but this influence is relatively weak $(19.97 \%$ on average for the whole group or $1.43 \%$ for a company). This result confirms the global question "Enigma": Why in exponential growth of technological progress and investment in innovation, labour productivity (single-factor or multi-factor) remains stagnant.

Assuming, that TFP, which is dominated by technological progress, has little impact on corporate growth, which is a quantitative indicator, a certain interest is to explore what its impact on returns, which is a high quality indicator on economic progress. For analysis and disclosure of connections and influences was compiled Table 2:

Table 2. Dynamics of returns and total factor productivity of industrial companies (2007-2017), \%

\begin{tabular}{|l|c|c|c|}
\hline \multicolumn{1}{|c|}{ Industrial companies } & $\Delta$ TFP & $\Delta$ ROA & $\Delta$ ROE \\
\hline 1. Sopharma AD & $-420,90$ & $-3,46$ & $-7,73$ \\
\hline 2. Sirma group AD & 206,36 & 3,65 & 3,56 \\
\hline 3. Korado Bulgaria AD & $-114,75$ & 21,01 & 25,76 \\
\hline 4. Hydraulic Elements and Systems AD & $-80,85$ & 5,91 & 5,88 \\
\hline 5. Alkomet AD & $-195,15$ & 1,32 & 0,65 \\
\hline 6. Neochim AD & 13,83 & 1,62 & 10,02 \\
\hline 7. Elhim Iskra AD & 32,41 & $-11,34$ & $-12,52$ \\
\hline 8. M+C Hydraulic AD & $-101,60$ & 4,02 & 1,62 \\
\hline 9. Yuri Gagarin AD & 101,51 & $-5,97$ & $-8,28$ \\
\hline 10. Monbat AD & 74,48 & $-6,83$ & $-9,31$ \\
\hline 11. Lavena AD & 164,37 & 9,58 & 9,47 \\
\hline 12. EMKA AD & 26,77 & 2,43 & 5,64 \\
\hline 13. Formoplast AD & 462,01 & 0,43 & 2,22 \\
\hline 14. Asenova Krepost AD & 31,20 & 6,14 & 0,38 \\
\hline
\end{tabular}

The analysis of the data in Table 2 shows that the first group of companies with the highest growth of TFP and corporate growth (Sirma group $\mathrm{AD}$, Formoplast $\mathrm{AD}$ and Lavena $\mathrm{AD}$ ) has an increasing return on both assets and equity. The second group of companies (Yuri Gagarin AD and Monbat AD) has diffuse dynamics of TFP and ROI. The third group of companies with low and moderate growth and a positive impact on TFP, realize increasing returns with some fluctuations (Elhim Iskra $\mathrm{AD})$. In the fourth group of companies with negative influence of TFP on corporate growth dominates diversely mutation in return and productivity with one exception - Sopharma AD.
As a summary for the whole aggregate industrial companies, the impact analysis and the quantitative dimension shows:

- The TFP has had a positive impact on the increase of the operating efficiency (return on total assets), but this impact is very weak: $0.18 \%$ annual average per company;

- The impact of TFP on the growth of financial efficiency (return on equity) was also positive, but this influence was also very weak: $0.19 \%$ annual average per company.

In the spirit of research accuracy should be noted that these estimates are made based on a comparison of the series, and it is known, that parallel change is not always an indication of dependence and influence. 


\section{CONCLUSION}

In the end the following conclusions can be done:

1. As a subject were used public industrial companies of main Bulgarian Stock Exchange $A D$ - Sofia, because of their open nature, relatively good capitalization and availability of stock trading.

2. To define TFP at corporate level a model of the authors is used, which is a modification of Robert Solow's famous model for determining economic growth at national level.

3. Analysis of the factor impact on corporate growth shows that four groups of companies are formed:

Group I - with very high corporate growth and strong TFP impact on it;

Group II - with high corporate growth and significant influence of TFP on it;

Group III - with low and moderate corporate growth and a positive impact of TFP on it;

Group IV - with low and moderate corporate growth and a negative impact on total factor productivity

4. TFP is a complex factor that includes two opposite groups of factors:

Group I - stimulating corporate growth;

Group II - retaining corporate growth.

This is the reason that in many studies TFP to be called "multifactorial productivity":

- one-factor productivity (labour);

- multifactor productivity (Total Factor Productivity - TFP).

5. The group of companies with negative TFP has achieved low or moderate corporate growth for the analysed period (2007-2017) thanks to the other two major factors: capital and labour, with the dominant influence being on the added capital and significantly less of the increased capital and significantly less on rising labour costs. Thus, these two factors (especially capital expenditures) have compensated the negative impact of TFP retaining factors.

6. Generally, overall factor productivity - TFP has had a positive impact on the corporate growth of all industrial companies, but this influence is very weak - $1.43 \%$ annual average per company. Thus, the macro-grid of stagnation in productivity, despite the exponential growth of technological advances and investment in innovation, also poses serious questions to researchers in the field of microeconomics.

7. Assuming that corporate growth is a quantitative indicator, there is a certain interest in determining how TFP affects qualitative indicators and particular on the return specified in the following two options:

- Return on total assets;
- Return on equity.

8. The analysis of the results of all industrial companies shows that TFP has had a positive impact on business efficiency (return on total assets), but this influence is very weak: $0.18 \%$ annual average per company.

9. The influence of TFP on the growth of financial efficiency (return on equity) is also positive, but this influence is very weak: $0.19 \%$ annual average of a company. Naturally, the following mystery arises: Why is technological progress and innovation as the main components of multi-factor productivity so poorly influenced on business performance?

\section{REFERENCES}

1. Schwab, K., The Fourth Industrial Revolution. Plovdiv: Publishing house Hermes, p. 51, 2016.

2. Haskel, J. and Westlake, S., Capitalism without Capital. Sofia: East - West, 2018.

3. Konarev, A., Konstantinova, Sn. and Georgieva-G. V., Technological innovations and total factor productivity in dairy industry. - In: 8th International Scientific Conference "TechSys 2019" - Engineering, Technologies and systems, Technical University of Sofia, Plovdiv Branch, 2019. (in print)

4. Konstantinova, Sn. and Konarev, A., Corporate Growth and Total Factor Productivity in the Industrial Companies. In: Fourth International Scientific Conference "Business and Regional Development", At Trakia University - Stara Zagora, Bulgaria, Trakia Journal of Sciences, Volume 15, Supplement 1, pp. 191-194, 1312-1723 ISSN TJS (print); 1313-3551 - ISSN TJS (online), 2017.

5. Solow, R. M., Technical Change and the Aggregate Production. Review of Economics and Statistics, Vol. 39, №3, pp. 312-320, Aug., 1957.

6. Ganev, K., Measuring Total Factor Productivity: Growth Accounting for Bulgaria. Discussion papers of the BNB, DP / 48, pp. 8-9, 2005.

7. Konarev, A. and Konstantinova, Sn., Analysis of the economic activity of industrial companies. Plovdiv: Publishing house KSI, p. 227, 2017.

8. Todorov, I., The Economic Growth of Bulgaria in the Period of the Currency Board. //Economic Alternatives, Issue 3, 2015.

9. The Conference Board, Productivity Brief, 2015. - www.conference-board.org.

10.United States Department of Labor. Preliminary Multifactor Productivity Trends, 2014.https://www.dol.gov/olms/regs/complia nce/lm3_downloadpg.htm 